\title{
JOANNA POPOWICZ
}

\section{Entre la convención y la creatividad. Unidades fraseológicas con la palabra corazón en la traducción polaca de la novela El amor en los tiempos del cólera}

\author{
Palabras clave: traducción - García Márquez - fraseología - lingüística \\ cognitiva.
}

\section{Resumen}

El presente estudio investiga la traducción de las expresiones fijas que contienen la palabra corazón en la versión polaca de la novela El amor en los tiempos del cólera. Esta versión de la novela nunca ha sido objeto de estudios de traducción. El estilo de García Márquez es original y artístico, pero al mismo tiempo abunda en expresiones idiomáticas, que se suman a su calidad natural y auténtica. A menudo el autor modifica intencionalmente esas expresiones. Las expresiones idiomáticas, tanto las regulares como las modificadas, constituyen un desafío para un traductor. El estudio adopta el enfoque de la Lingüística cognitiva, que ha demostrado ser adecuada y eficaz en los trabajos de traductología de Elżbieta Tabakowska (2001, 2008), Krzysztof Hejwowski (2004, 2017) y Tomasz P. Krzeszowski (2016). El análisis ha revelado algunas dificultades en la traducción de estas expresiones, debido a la falta de equivalencia en diferentes niveles: en el nivel de contenido conceptual, constructivo, grado de convencionalidad y cohesión léxica. Se analizan y discuten las estrategias utilizadas por el traductor para resolver esos problemas.

\section{Introducción}

El presente estudio se centra en las expresiones fijas con el vocablo corazón en la traducción al polaco de la novela de Gabriel García Márquez El amor en los tiempos del cólera. Su objetivo principal es analizar y describir los problemas con los que se enfrentó el traductor, así como las estrategias que empleó para solucionarlos. La traducción en cuestión, realizada por Carlos Marrodán 
Casas en 1994, es la única versión polaca de esta popular novela. Además, nunca ha sido sometida a estudio traductológico. Cabe mencionar que Carlos Marrodán Casas recibió en 1995 el Premio de la Asociación de Escritores Polacos por esta traducción.

El objeto de estudio está constituido por las unidades fraseológicas porque el estilo de García Márquez, aun siendo original y artístico, abunda en estas expresiones convencionales, que le aportan rasgos de naturalidad y expresividad. Además, el autor muchas veces recurre a la manipulación creativa de tales expresiones ${ }^{1}$. Las unidades fraseológicas con la palabra corazón desempeñan una función especial en la novela porque en su mayoría se refieren a los sentimientos, que constituyen el tema principal del libro. Los sentimientos, siendo conceptos abstractos, intangibles y, por ello, difíciles de expresar con palabras, suelen describirse de manera metafórica. Desde un punto de vista conceptual y lingüístico, el corazón es el centro emocional del ser humano, tanto en la cultura española como en la polaca ${ }^{2}$. Utilizando los términos de la lingüística cognitiva, se puede decir que en español y en polaco funciona la metáfora conceptual EL CORAZÓN ES EL CENTRO EMOCIONAL DEL SER HUMANO, que se manifiesta en ambas lenguas de manera convencional en forma de varias unidades fraseológicas ${ }^{3}$. En El amor en los tiempos del cólera la convención se mezcla con la creatividad no solo en el nivel lingüístico, sino también en el nivel del contenido. La novela parodia numerosos tópicos propios de los folletines de lágrimas del siglo XIX, como la enfermedad de amor o el pacto amoroso ${ }^{4}$. El lenguaje y el contenido forman una unidad coherente: el efecto de la sátira de la literatura amatoria es reforzado por el uso de expresiones convencionales y expresivas, tales como las unidades fraseológicas con la palabra corazón, que corroboran la impresión de exaltación y exageración típicas de las novelas de amor. Cabe mencionar que García Márquez modifica los tópicos mencionados asociando, por ejemplo, la enfermedad de amor con los síntomas de una enfermedad muy poco romántica, el cólera. Asimismo, a veces se alteran

${ }^{1}$ La modificación de unidades fraseológicas se denomina manipulación creativa o desautomatización. Cf. B. Gundersen, "Las unidades fraseológicas y su traducción literaria", en: M.P. Blanco García, P. Martino Alba (eds.), Traducción y multiculturalidad, Madrid, Universidad Complutense de Madrid, 2006, pp. 219-227. Para más información sobre la desautomatización en las novelas de García Márquez consúltese: V. Díaz Orozco, F.O. Zuluaga Gómez, L. Ciro, "Funciones de los fraseologismos en la novelística de García Márquez: el caso de la desautomatización", Revista Virtual Universidad Católica del Norte, 26, 2009, pp. 1-25, <http://revistavirtual.ucn.edu.co>, 20 de diciembre de 2019.

2 Cf. A. Pajdzińska, "Jak mówimy o uczuciach? Poprzez analizę frazeologizmów do językowego obrazu świata”, en: J. Bartmiński (ed.), Językowy obraz świata, Lublin, Wydawnictwo UMCS, 1999, p. 91.

3 Cf. un estudio sobre las metáforas conceptuales relacionadas con el corazón: I. Kraska-Szlenk, "Serce w języku polskim i moyo w suahili w metaforach wyrażających emocje", en: A. Duszak, N. Pawlak (eds.), Anatomia szczęścia. Emocje pozytywne w językach i kulturach świata, Warszawa, Wydawnictwa Uniwersytetu Warszawskiego, 2005, pp. 137-145.

4 M. Cabello Pino, "El influjo cervantino en El amor en los tiempos del cólera", La palabra, 26, 2015, p. 55. 
las convenciones lingüísticas. Ambos, la forma y el contenido, vacilan entre lo original y lo convencional.

Tanto en la lingüística polaca como en la española se han elaborado varias clasificaciones de unidades fraseológicas ${ }^{5}$. En este estudio las unidades fraseológicas (o fraseologismos) se definen como unidades léxicas formadas por más de dos palabras gráficas en su límite inferior que se caracterizan por la fijación en la lengua.

El estudio sigue la línea de investigación propuesta por Elżbieta Tabakows$\mathrm{ka}^{6}$, que emplea las herramientas elaboradas por la lingüística cognitiva en los estudios traductológicos ${ }^{7}$. Según Tabakowska, "la equivalencia «estilística» se basa en gran medida en las dimensiones de la estructuración conceptual en el sentido en el que este término se usa en la gramática cognitiva"8. La estructuración conceptual (en inglés: construal y en polaco: obrazowanie) se refiere a la habilidad del hombre de percibir y presentar la misma situación de diferentes maneras ${ }^{9}$. Otro concepto importante a la hora de estudiar los fraseologismos, proveniente de la gramática cognitiva, es el del grado de convencionalización. Para Ronald Langacker, la convencionalización es inevitablemente una cuestión de grado, de ahí que no sea posible establecer una frontera precisa entre unidades fraseológicas y combinaciones de palabras libres ${ }^{10}$.

Las expresiones fijas, tanto convencionales como modificadas, constituyen un desafío para el traductor, el cual tiene que buscar equivalencias en el nivel del significado, de la estructuración conceptual y del grado de convencionalización ${ }^{11}$. Todos estos aspectos influyen en las asociaciones que se forman en la mente del receptor ${ }^{12}$. En el caso de las unidades fraseológicas analizadas en este trabajo, para conseguir el mismo efecto que se obtiene en el texto origen - no solo el mismo sentido, sino también los mismos rasgos de estilo, tales como la expresividad exagerada que parodia los folletines de lágrimas-

5 Para una panorámica de estas propuestas, véanse: G. Corpas Pastor, Manual de Fraseología Española, Madrid, Gredos, 1996, y M. Sosiński, Fraseología comparada del polaco y del español, Warszawa, Wydawnictwa Uniwersytetu Warszawskiego, 2009.

${ }^{6}$ E. Tabakowska, Językoznawstwo kognitywne a poetyka przekładu, Kraków, Universitas, 2001; E. Tabakowska, O przektadzie na przykładzie. Rozprawa tłumacza z Europa Normana Davi$s a$, Kraków, Społeczny Instytut Wydawniczy Znak, 2008.

${ }^{7}$ En los últimos años se han ido desarrollando las teorías traductológicas que se sirven de los conceptos y métodos elaborados en el paradigma de la lingüística cognitiva. Para más información mirénse: K. Hejwowski, “Translating minds: Cognitivism and translation”, LaMiCuS, 1, 2017, pp. 54-66; T.P. Krzeszowski, The Translation Equivalence Delusion. Meaning and Translation, Frankfurt, Peter Lang, 2016.

8 “[...] ekwiwalencja «stylistyczna» zasadza się w znacznej mierze na wymiarach obrazowania w rozumieniu gramatyki kognitywnej”, E. Tabakowska, Językoznawstwo kognitywne a poetyka przektadu, ed. cit., pp. 97-98.

9 R. Langacker, Gramatyka kognitywna. Wprowadzenie, Kraków, Universitas, 2009, p. 85.

10 Ibidem, p. 63.

11 Cf. E. Tabakowska, O przekładzie na przykładzie, ed. cit., pp. 169-187; E. Tabakowska, Językoznawstwo kognitywne a poetyka przekładu, ed. cit., pp. 90-97.

12 En la misma línea, véase: K. Hejwowski, op. cit., pp. 59-60. 
el traductor debería encontrar en la lengua meta expresiones que tengan el mismo significado (denotativo y connotativo), se sirvan de las mismas imágenes metafóricas y estén igualmente fijadas en la lengua. Sin embargo, lograr la equivalencia en todos estos niveles no siempre es posible ${ }^{13}$.

Se pueden distinguir cinco estrategias básicas para la traducción de unidades fraseológicas ${ }^{14}$ : (1) el uso de una unidad fraseológica con forma y significado iguales o muy similares; (2) el uso de un equivalente funcional, o sea, una unidad fraseológica que tiene un significado parecido, pero se sirve de una imagen metafórica diferente; (3) la traducción sintagmática; (4) el uso de un equivalente que no es una unidad fraseológica; (5) la omisión de la unidad fraseológica. En el análisis aquí presentado se han observado las cuatro primeras estrategias.

\section{El análisis del material lingüístico}

La palabra corazón aparece en el libro 87 veces, de las que 77 son usos metafóricos. Entre ellos, doce expresiones se clasificaron como unidades fraseológicas. El criterio en la mayoría de los casos fue la presencia de la unidad en los diccionarios (DFDEA, DUE, DLE). Además, se encontraron dos expresiones que constituyen modificaciones creativas de unidades fraseológicas. Tales expresiones se incluyen en el estudio porque también en ellas la convencionalización de la unidad original desempeña un papel estilístico importan$t^{15}$. Los resultados del estudio se presentan según el criterio de la estrategia de traducción utilizada.

\subsection{El uso de una unidad fraseológica con la forma y el significado igual o muy similar}

1) ablandarle el corazón a alguien (ATC: 179) (REDES, s.v. corazón) ${ }^{16} \rightarrow$ zmiękczyć komuś serce (MCZ: 177) (WSFJP, s.v. serce)

$13 C f:$ : "Translation often involves a tension - a difficult choice between what is typical and what is accurate", M. Baker, In Other Words: a Coursebook on Translation, London-New York, Routledge, 1999, p. 68.

${ }^{14}$ Cf. K. Hejwowski, Kognitywno-komunikacyjna teoria przekładu, Warszawa, Wydawnictwo Naukowe PWN, 2004, p. 66; M. Baker, op. cit., pp. 72-78; J. Wesoła, N. Paprocka, "Frazemy we francuskim i hiszpańskim przekładzie Małej Apokalipsy", en: E. Skibińska (ed.), Konwicki i tlumacze, Łask, Oficyna Wydawnicza Leksem, 2006, p. 209; G. Corpas Pastor, "Acerca de la (in) traducibilidad de la fraseología", en: idem (ed.), Las lenguas de Europa: Estudios de fraseografia, fraseología y traducción, Granada, Editorial Comares, 2000, pp. 483-522.

15 V. Díaz Orozco; F.O. Zuluaga Gómez; L. Ciro, op. cit., p. 6.

${ }^{16}$ Entre paréntesis se indica la página de la novela y el diccionario en el que aparece la unidad fraseológica en cuestión. 
2) abrir el corazón a alguien (ATC: 280) (DFDEA, s.v. corazón) $\rightarrow$ otworzyć przed kimś serce ${ }^{17}$ (MCZ: 281)

3) con la mano en el corazón (ATC: 156) (DFDEA, s.v. mano) $\rightarrow z$ ręka na sercu (MCZ: 154) (WSFJP, s.v. ręka)

4) no tener corazón para hacer algo (ATC: 105) (DUE, s.v. corazón) $\rightarrow$ nie mieć serca czegoś zrobić (MCZ: 102) (WSFJP, s.v. serce)

$5)$ de todo corazón (ATC: 336) (DFDEA, s.v. corazón) $\rightarrow$ z całego serca (MCZ: 338) (WSFJP, s.v. serce)

6) el corazón le dice algo a alguien (ATC: 397) (DFDEA s.v. corazón) $\rightarrow$ serce coś komuś mówi (MCZ: 403) (WSFJP, s.v. serce)

Los equivalentes utilizados presentan el mismo significado (o un significado muy similar), el mismo grado de convencionalización y comparten la misma base metafórica. Sin embargo, se ha observado un problema relacionado con las propiedades combinatorias de la expresión $z$ całego serca 'de todo corazón', que no suena muy natural en una construcción causativa:

Fue así como se enteró de que Lorenzo Daza había muerto, y se alegró de todo corazón [...]. (ATC: 336)

I tak oto dowiedział się, że Lorenzo Daza zmarł i nowina ta ucieszyła go z całego serca [...]. (MCZ: 338)

Cierta restricción combinatoria de la expresión z całego serca se ve confirmada por los datos del corpus NKJP, donde esta construcción se utiliza solamente en oraciones en las que el sujeto gramatical corresponde a la persona que experimenta el sentimiento.

\subsection{El uso de un equivalente funcional}

(7) a corazón abierto (ATC: 130 ) (DFDEA, s.v. corazón) $\rightarrow$ z całego serca ('de todo corazón') (MCZ: 128) (WSFJP, s.v. serce)

(8) con el corazón (ATC: 26) (DUE, s.v. corazón) $\rightarrow$ z głębi serca (lit. 'desde el fondo del corazón'18) (MCZ: 23) (WSFJP, s.v. serce)

(9) el corazón le da un salto a alguien (ATC: 333) (DFDEA, s.v. salto) $\rightarrow$ serce się komuś ściska ('el corazón se le encoge a alguien') (MCZ: 218) (SFE, s.v. serce)

(10) el corazón se le hiela a alguien (ATC: 476) (DFDEA, s.v. corazón) $\rightarrow$ serce komuś / w kimś zamiera (lit. 'el corazón se le para a alguien') (MCZ: 482) (WSFJP, s.v. serce)

17 A. Pajdzińska, op. cit., p. 93.

18 Se utiliza la abreviación lit. (literalmente) en el caso de las unidades fraseológicas polacas que no tienen un equivalente en español y tienen que traducirse literalmente. 
(11) *llevaba los dientes apretados para que no se le saliera el corazón por la boca ${ }^{19}$ (ATC: 320$) \rightarrow$ zaciskała zęby, by serce nie wyskoczyto jej z gardta (lit. 'apretaba los dientes para que el corazón no le saltara de la garganta') (MCZ: 210)

La unidad fraseológica a corazón abierto se tradujo como z całego serca ('de todo corazón') a pesar de tener un equivalente polaco: $z$ otwartym sercem ${ }^{20}$ :

[...] al cabo de tantos años habían depuesto sus prejuicios tribales y lo admitieron a corazón abierto como uno de los suyos. (ATC: 130)

[...] po tylu latach odłożyli na bok plemienne uprzedzenia, przyjmując go z całego serca jako jednego spośród swoich. (MCZ: 128)

Como se ha podido comprobar en NKJP, la expresión $z$ otwartym sercem suele usarse en contextos en los que se saluda o se recibe a alguien, de ahí que pueda emplearse en este caso. Sin embargo, es una construcción mucho menos fijada en la lengua que $z$ całego serca, lo cual se puede observar en NKJP: la expresión $z$ otwartym sercem aparece allí 24 veces, mientras que $z$ całego serca lo hace 732 veces. Es posible que el traductor optara por la expresión z całego serca por su mayor grado de convencionalización.

En la siguiente traducción aparece un problema relacionado con las restricciones combinatorias de las unidades fraseológicas:

Se fijó en ella con el corazón, se fijó en su luto intenso, en la dignidad de su congoja [...]. (ATC: 26)

Przyjrzał się jej z głębi serca, przyjrzał się jej ciężkiej żałobie, godności jej cierpienia [...]. (MCZ: 23)

La oración española tiene un carácter bastante convencional, mientras que la versión polaca parece innovadora. La búsqueda en NKJP ha mostrado que z głębi serca se suele utilizar para describir la manera de comunicar algo: decir, desear, gritar, dar las gracias, pedir perdón. Esta expresión, a pesar de ser idiomática, sigue siendo composicional en el sentido de que evoca la imagen de algo que brota del fondo del corazón; puede ser un sentimiento, un suspiro, un grito, una palabra, pero no puede ser algo tan abstracto como la actividad de fijarse en alguien. La decisión del traductor se justifica con el carácter artístico de la obra, que permite soluciones menos convencionales.

La expresión el corazón le da un salto a alguien significa que alguien sufre una impresión súbita muy fuerte y normalmente desagradable (DFDEA, s.v. salto). El corazón le da un salto a Florentino Ariza cuando encuentra el panteón de Fermina Daza y su esposo con un epitafio común. La imagen del corazón que se encoge, empleada en la traducción, evoca asociaciones algo diferentes:

${ }^{19}$ El asterisco señala las unidades fraseológicas modificadas por García Márquez.

20 A. Pajdzińska, op. cit., p. 93. 
se utiliza para hablar sobre sentimientos negativos menos súbitos, sobre todo de pena, tristeza o compasión. Probablemente no se utilizara un equivalente exacto: czyjeś serce podskoczyło, porque en polaco esta expresión no es convencional y puede interpretarse de maneras diversas. Incluso se puede suponer que se asocia más con la alegría que con la tristeza. En los diccionarios modernos esta unidad no se cita, pero en un diccionario fraseológico del año 1899 aparece la expresión serce skacze (z radości) 'el corazón salta (de alegría)'21.

La expresión helárse(le) el corazón a alguien, que no tiene un equivalente total en polaco, se sustituyó por serce komuś zamarlo. Las dos expresiones evocan imágenes parecidas del corazón que deja de latir. Además, designan el mismo tipo del sentimiento y son igualmente convencionales.

Como ya se ha mencionado, García Márquez a veces se sirve de la manipulación creativa de unidades fraseológicas con diversos fines estilísticos. En el ejemplo (11) se puede apreciar la unidad fraseológica modificada, que en la versión polaca se sustituyó por un equivalente funcional, también alterado. La expresión española constituye una modificación de la unidad fraseológica el corazón le sube a alguien a la boca / a la garganta, que significa: 'sentir gran ansiedad o desasosiego' (DFDEA, s.v. corazón). En polaco existen expresiones parecidas, pero no se sirven de la imagen de la boca, sino solo de la garganta: serce komuś podchodzi / skacze do gardta 'el corazón le sube / salta a alguien a la garganta', serce komuś mało nie wyskoczy gardłem / przez gardło / z gardła 'el corazón casi le salta a alguien de la garganta / por la garganta' (WSFJP, s.v. serce). García Márquez altera la expresión fija, añadiendo la imagen de apretar los dientes. Por ello la unidad fraseológica se desautomatiza, o sea, se actualiza su significado literal, y la oración resulta más plástica y expresiva. El traductor consiguió reflejar este mecanismo estilístico, identificando la base fraseológica de la expresión innovadora y sustituyendo la imagen de la boca por la de la garganta para mantener el efecto del juego con la convención.

\subsection{La traducción sintagmática}

(12) el corazón se lo había pedido ${ }^{22}$ (ATC: 63$) \rightarrow$ serce wymogło to na nim (lit. 'el corazón le obligó a eso') (WCZ: 60)

(13) *también él tenía su corazón escondido (ATC: 488) $\rightarrow$ tez miat swoje serduszko w ukryciu (lit. 'también tenía su corazoncito escondido') (MCZ: 495)

Como indica Hejwowski, esta técnica es posible "[...] solo en casos específicos, cuando la unidad original es «transparente» (comprensible en la cultura

21 A. Krasnowolski, Stowniczek frazeologiczny. Poradnik dla piszacych, Warszawa, Druk Lepperta i S-ki, 1899, p. 186.

22 Esta expresión, aunque no aparece en ningún diccionario, se puede considerar fijada en la lengua. Al buscar la frase el/mi corazón me lo pide en Google se obtuvieron 51700 resultados. En cambio, la expresión polaca serce prosi/poprosito mnie o to no se encontró ni en Google ni en NKJP. 
meta) y solo en algunos tipos de textos, en los que el receptor está preparado para cierta innovación, invención lingüística"23.

En los dos casos citados se cumplen las condiciones mencionadas. En primer lugar, el lector de una novela está preparado para cierta innovación lingüística. En segundo lugar, las traducciones polacas resultan transparentes. Aunque no son convencionales en sí mismas, se entienden perfectamente, porque hacen referencia a otras expresiones fijas, en las que se emplean imágenes metafóricas parecidas: głos serca 'la voz del corazón' ktoś nie ma serca 'alguien no tiene corazón' (WSFJP, s.v. serce).

La expresión también él tenía su corazón escondido constituye una modificación de la expresión fija alguien también tiene su corazón / corazoncito (DFDEA: 320). La expresión original se ha ampliado con la palabra escondido, creando una imagen más literal. Dicha expresión fija no tiene un equivalente en polaco y por eso se tradujo sintagmáticamente. Sin embargo, en la traducción se utiliza el diminutivo serduszko 'corazoncito', que no aparece en la versión original. Probablemente se trate aquí de una forma de compensación de la falta de convencionalidad de la expresión polaca, que, sin ninguna modificación, podría parecer demasiado literal. Al utilizar el diminutivo, el traductor intenta sugerir al lector la interpretación metafórica y obtener un resultado más coloquial, parecido al efecto en el texto origen. Es posible que la traducción haya sido influida por la expresión convencional española también tener su corazoncito (DFDEA, s.v. corazón).

\subsection{El uso de un equivalente que no es una unidad fraseológica}

(14) con la mano en el corazón (ATC: 45) (DFDEA, s.v. mano) $\rightarrow$ szczerze ('sinceramente') (MCZ: 42)

Éste es el único caso en el que en la traducción la unidad fraseológica se sustituye por una palabra. En la versión original la expresión fija con la mano en el corazón se combina con el verbo preguntarse:

[...] nunca se lo habían preguntado con la mano en el corazón [...]. (ATC: 45)

[...] nigdy jednak nie zadali sobie szczerze tego pytania [...]. (MCZ: 42)

Parece que el equivalente polaco $z$ ręka na sercu presenta mayor restricción combinatoria y no sonaría bien en este contexto. La búsqueda en NKJP muestra que suele acompañar a los verbos declarativos como powiedzieć 'decir' y przyznać 'admitir'.

23 "[...] tylko w rzadkich, specyficznych przypadkach, kiedy oryginalny idiom jest «przejrzysty» (zrozumiały w kulturze docelowej) i tylko w pewnych typach tekstów, w których odbiorca przygotowany jest na pewne nowatorstwo, inwencję językową". K. Hejwowski, Kognitywno-komunikacyjna teoria przekładu, ed. cit., p. 66. 


\section{Conclusiones}

El análisis presentado ha mostrado algunas dificultades con las que se enfrentó Carlos Marrodán Casas en el proceso de traducción de unidades fraseológicas con la palabra corazón. El problema principal fue la falta de unidades fraseológicas equivalentes en la lengua meta. Muchas veces no existe un equivalente total que pueda sustituir la expresión original en el plano del significado, de la estructuración conceptual y de la convencionalización. Con el fin de resolver este problema, se emplearon varias estrategias de traducción. Además, se han observado problemas relacionados con las restricciones combinatorias de los fraseologismos, las cuales a veces resultan de su estructura metafórica. En el caso de las unidades fraseológicas modificadas, el traductor, aparte de identificar la unidad y su equivalente, tuvo que reconstruir el mecanismo de su manipulación creativa. El estudio ha evidenciado que la mayoría de las unidades fraseológicas analizadas se sustituyeron por un equivalente total o funcional. En definitiva, se puede suponer que el traductor intentó ser fiel al texto original, conservando las expresiones fijas siempre y cuando fuera posible. Como se ha indicado en la introducción, tales expresiones representan un papel importante en el lenguaje de la novela, de ahí que las elecciones traductológicas efectuadas contribuyan a la equivalencia estilística entre el texto origen y el texto meta. La suma de estas elecciones influye en cierto grado en la totalidad de la traducción ${ }^{24}$ y su recepción por el lector polaco.

\section{Referencias bibliográficas}

BAKER Monica

1999 In Other Words: a Coursebook on Translation, London-New York, Routledge.

CABELLO PINO Manuel

2015 "El influjo cervantino en El amor en los tiempos del cólera", La palabra, 26, pp. 47-58. CORPAS PASTOR Gloria

2000 “Acerca de la (in) traducibilidad de la fraseología”, en: Corpas Pastor G. (ed.), Las lenguas de Europa: Estudios de fraseografia, fraseología y traducción. Granada, Editorial Comares, pp. 483-522.

DÍAZ OROZCO Viviana, ZULUAGA GÓMEZ Octavio Francisco, CIRO Lirian

2009 "Funciones de los fraseologismos en la novelística de García Márquez: el caso de la desautomatización", Revista Virtual Universidad Católica del Norte, 26, pp. 1-25, <http:// revistavirtual.ucn.edu.co>, 20 de diciembre de 2019.

GUNDERSEN Bente

2006 "Las unidades fraseológicas y su traducción literaria", en: Blanco García M.P., Martino Alba P. (eds.), Traducción y multiculturalidad, Madrid, Universidad Complutense de Madrid, pp. 219-227.

HEJWOWSKI Krzysztof

2004 Kognitywno-komunikacyjna teoria przekładu, Warszawa, Wydawnictwo Naukowe PWN. 2017 “Translating minds: Cognitivism and translation”, LaMiCuS, 1, pp. 54-66.

24 J. Wesoła, N. Paprocka, op. cit., p. 215. 
KRZESZOWSKI Tomasz P.

2016 The Translation Equivalence Delusion. Meaning and Translation, Frankfurt, Peter Lang. KRASNOWOLSKI Antoni

1899 Stowniczek frazeologiczny. Poradnik dla piszacych, Warszawa, Druk Lepperta i S-ki.

PAJDZIŃSKA Anna

1999 "Jak mówimy o uczuciach? Poprzez analizę frazeologizmów do językowego obrazu świata", en: Bartmiński J. (ed.), Językowy obraz świata, Lublin, Wydawnictwo UMCS, pp. 83-101.

KRASKA-SZLENK Iwona

2005 "Serce w języku polskim i moyo w suahili w metaforach wyrażających emocje", en: Duszak A., Pawlak N. (eds.), Anatomia szczęścia. Emocje pozytywne w językach i kulturach świata, Warszawa, Wydawnictwa Uniwersytetu Warszawskiego, pp. 137-145.

TABAKOWSKA Elżbieta

2001 [1993] Językoznawstwo kognitywne a poetyka przekładu, Kraków, Universitas.

2008 [1999] O przektadzie na przykładzie. Rozprawa tlumacza z Europa Normana Davisa, Kraków, Społeczny Instytut Wydawniczy Znak.

WESOŁA Justyna, PAPROCKA Natalia

2006 "Frazemy we francuskim i hiszpańskim przekładzie Małej Apokalipsy", en: Skibińska E. (ed.), Konwicki i ttumacze, Łask, Oficyna Wydawnicza Leksem, pp. 205-216.

\section{Fuentes (acrónimos usados)}

ATC: GARCÍA MÁRQUEZ Gabriel

2008 [1985] El amor en los tiempos del cólera, Random House Mondadori, Barcelona.

DFDEA: SECO Manuel (ed.)

2004 Diccionario Fraseológico Documentado del Español Actual, Madrid, Aguilar lexicografía.

DLE: REAL ACADEMIA ESPAÑOLA

2001 Diccionario de la lengua española, 22. ${ }^{\mathrm{a}}$ ed., versión 23.3 en línea, $<\mathrm{https}$ ://dle.rae.es>, 20 de diciembre de 2019.

DUE: MOLINER María

2008 Diccionario de uso del español, Madrid, Gredos, versión electrónica en DVD.

MCZ: GARCÍA MÁRQUEZ Gabriel

2004 [1994] Miłość w czasach zarazy, trad. Carlos Marrodán Casas, Warszawa, Warszawskie Wydawnictwo Literackie MUZA SA.

NKJP: Narodowy Korpus Języka Polskiego, <http://nkjp.pl>, 20 de diciembre de 2019.

SFE: GŁUCH Wojciech

2003 Stownik frazeologiczny, Wrocław, Wydawnictwo Europa.

WSFJP: MÜLDNER-NIECKOWSKI Piotr

2003 Wielki słownik frazeologiczny języka polskiego, Warszawa, Świat Książki.

Estudios Hispánicos 28, 2020

(C) for this edition by CNS 


\title{
Between convention and creativity: Idioms with the word corazón in the Polish translation of the novel El amor en los tiempos del cólera
}

Keywords: translation — García Márquez — idioms — cognitive linguistics.

\begin{abstract}
The present study investigates the translation of idioms containing the word corazón 'heart' in the Polish version of the novel El amor en los tiempos del cólera. This version of the novel has never been the object of translation studies. The style of García Márquez is original and artistic, but at the same time it abounds with idiomatic expressions, which add to its natural and authentic quality. The author often intentionally modifies these expressions. Idiomatic expressions, both regular and modified, constitute a challenge for a translator. The study adopts the cognitive linguistics approach, which has been proved suitable and effective in translation studies by authors such as Elżbieta Tabakowska (2001, 2008), Krzysztof Hejwowski (2004, 2017) and Tomasz P. Krzeszowski (2016). The analysis has revealed some difficulties in translating idiomatic expressions, resulting from the lack of equivalence on different levels: on the level of conceptual content, construal, degree of conventionality and lexical cohesion. The strategies used by the translator in order to solve these problems are analyzed and discussed.
\end{abstract}

Fecha de recepción: 20 de enero de 2020

Fecha de aceptación: 8 de mayo de 2020 